\title{
Impact of adherence on growth response during the first 2 years of growth hormone treatment
}

\author{
Antonio de Arriba Muñoz $\mathbb{1}^{1,2} \cdot$ Vanesa Cancela Muñiz ${ }^{3}$ José Juan Alcón Saez ${ }^{4}$ Anunciación Beisti ${ }^{5}$. \\ Enrique Llovet $^{6} \cdot$ José Ignacio Labarta Aizpún ${ }^{1,2}$
}

Received: 3 July 2020 / Accepted: 18 November 2020

(c) Springer Science+Business Media, LLC, part of Springer Nature 2020

\begin{abstract}
Purpose Adherence to growth hormone $(\mathrm{GH})$ treatment impacts clinical outcomes. The aim of this study is to assess the impact of adherence to rhGH treatment ( 2 years) on auxological outcomes.

Methods Multicentric, retrospective observational study in rhGH-naïve GHD/SGA children treated with Saizen ${ }^{\circledR}$ during $\geq 2$ years. Growth response was assessed by evaluating the change in height standard deviation score ( $\Delta \mathrm{H}$ SDS) and the index of responsiveness (IoR). Adherence was monitored using EasyPod ${ }^{\mathrm{TM}}$ Connect device.

Results A total of 110 patients ( 3 Spanish centers) were evaluable (GHD $n=76$, SGA $n=34$ ). Adherence was 95.6 and 93.9\% (year 1, 2). SGA and GHD children showed an increase of $0.6 \mathrm{~cm} /$ year and $1.1 \mathrm{~cm} /$ year for each $10 \%$ adherence modification. Lower adherence was observed in patients with lower pretreatment height velocity (HV) and in patients whose parents had a lower level of education. A positive correlation between index of responsiveness (IoR) during the first and second years with HV SDS during the second year and between IoR2 and adherence (year 1,2) was observed. The frequency of patients with HV $>1 \mathrm{SD}$ was higher $(p=0.025)$ among patients with adherence $>90 \%$. The best model to predict the height gain $(\mathrm{cm})$ reaching an adjusted $\mathrm{R}$ squared of 0.489 involved percentage of adherence, Tanner stage, pretreatment $\mathrm{HV}$, dose of $\mathrm{rhGH}$, and whether the treatment was initiated before or after puberty.

Conclusions Adherence during the first 2 years of response was very high $>90 \%$ and showed a negative association with age, pretreatment $\mathrm{HV}$ and treatment duration and a positive correlation with the level of parent education.
\end{abstract}

Keywords Adherence $\cdot$ Growth hormone $\cdot$ Height velocity $\cdot$ Treatment response

\begin{tabular}{|c|c|}
\hline \multirow{2}{*}{\multicolumn{2}{|c|}{ Abbreviations }} \\
\hline & oreviations \\
\hline $\mathrm{Ae}$ & S adverse events \\
\hline $\mathrm{CI}$ & confidence interval \\
\hline$凶$ & $\begin{array}{l}\text { Antonio de Arriba Muñoz } \\
\text { adearriba@salud.aragon.es }\end{array}$ \\
\hline 1 & $\begin{array}{l}\text { Paediatric Endocrinology, Hospital Universitario Miguel Servet, } \\
\text { Zaragoza, Spain }\end{array}$ \\
\hline 2 & Instituto de Investigación Sanitaria Aragón, Zaragoza, Spain \\
\hline 3 & $\begin{array}{l}\text { Paediatric Endocrinology, Hospital Universitario de Donostia, } \\
\text { San Sebastian, Spain }\end{array}$ \\
\hline 4 & $\begin{array}{l}\text { Paediatric Endocrinology. Paediatrics and Obstetrics-Gynaecology } \\
\text { Department, Consorcio Hospital General Universitario de } \\
\text { Valencia, Valencia, Spain }\end{array}$ \\
\hline 5 & $\begin{array}{l}\text { Paediatric Endocrinology, Fundación Hospital de Calahorra, } \\
\text { Calahorra, La Rioja, Spain }\end{array}$ \\
\hline & Head of Biometry, Syntax for Science, Palma, Spain \\
\hline
\end{tabular}

\section{Abbreviations} bone age confidence interval

Published online: 07 December 2020
eCRF electronic Case Report Form

$\mathrm{GH}$ growth hormone

GHD growth hormone deficiency

GLM general linear models

HV height velocity

HV0 pretreatment HV

HV1 HV in the first year

HV2 HV in the second year

IoR index of responsiveness

ISS idiopathic short stature

IGF-1 insulin-like growth factor-1

iGHD idiopathic GH deficiency

rHGH recombinant human $\mathrm{GH}$

SGA small for gestational age

SDS standard deviation score

TH target height

WHO World Health Organization 


\section{Introduction}

Growth response is considered to be highly variable. Different prediction models have showed age at start, treatment duration, and dose of growth hormone $(\mathrm{GH})$ as predictive factors of growth response. Adherence to treatment has an important effect on growth in patients receiving recombinant human growth hormone (rhGH). However, none of the prediction models included adherence into their models, because it is very difficult to assess adherence accurately $[1,2]$.

The main goal of the rhGH treatment, in small for gestational age (SGA) and growth hormone deficiency (GHD) patients with reduced height, is to allow patients to quickly attain compensatory growth, eventually reaching the target height (TH) standard deviation score (SDS), followed by a maintenance phase, a proper pubertal height gain, and an adult height close to their TH [3].

According to the World Health Organization, adherence to treatment is a worldwide problem $[4,5]$. Previous studies have demonstrated the importance of adherence in $\mathrm{rhGH}$ treatment [6,7], although the adherence assessment used proved somewhat unreliable. For instance, the use of nonelectronic rhGH injection devices makes it highly difficult to obtain an objective assessment of compliance. Moreover, the significant variability in methods of detection and definitions of adherence utilized in studies must also be considered [8]. Newly available electronic or automatic administering devices are quickly becoming a highly useful tool in monitoring adherence to rhGH treatment [9]. Adherence data for patients using the EasyPod ${ }^{\mathrm{TM}}$ electronic device are both more accurate and easier to obtain than pharmacy dispensing data. These developments facilitate the early detection of suboptimal compliance to treatment, allowing these problems to be corrected as soon as they occur [9].

Several studies have attempted to design predictive models for treatment responses to rhGH by combining diverse auxological and biochemical variables [10-12]. However, while these studies have had varying degrees of success, very few have considered how adherence to rhGH affects the desired clinical outcome [2], despite the common knowledge that compliance is frequently suboptimal. Furthermore, potentially modifiable factors associated with pediatric nonadherence to rhGH treatment is also been looked for [13].

In the recent Spanish DATAC study, the height velocity (HV) SDS after 1-year treatment with rhGH was explained $(\mathrm{R} 2=0.511)$ as a function of the $\mathrm{TH}$, the bone age (BA) delay, the pretreatment $\mathrm{HV}$, and the adult height prognosis [10]. However, in this study, adherence to the rhGH treatment was not considered. Another example may be observed in the EasyPod ${ }^{\mathrm{TM}}$ Connect Observational Study
(ECOS), where the long-term outcomes of rhGH therapy (Easypod $^{\mathrm{TM}}$ electronic device) in rhGH-naïve pediatric subjects from 24 national studies were assessed. This study described the high compliance rates of patients with Saizen [8], but it was not specifically designed to determine the impact of adherence to the rhGH treatment on clinical outcomes. Therefore, it is necessary to assess the importance of optimal vs. suboptimal adherence by studying its impact on auxological outcomes, such as $\mathrm{HV}$ and height gain.

The correlation between a high adherence rate and an optimal clinical response during the first year of rhGH treatment was consistently reported [6, 14]. However, this relation might be influenced by the intensity of the catch-up effect during the first year of treatment.

Furthermore, a decrease in adherence after the first year of rhGH treatment was reported [14]. Adherence became less important to subjects as the height SDS approached the TH SDS during the compensatory growth phase, before entering the maintenance growth phase in which the $\mathrm{HV}$ is normal.

Therefore, extending the assessment of adherence and its relevance until the second year (continuing through the compensatory growth phase) would allow for a better definition of the trade-off between rhGH treatment and clinical outcomes. This extension would also contribute to identifying a higher proportion of less adherent patients, allowing for the development of a more reliable growth predictive model.

The primary objective of this study is to assess the possible relationship between adherence to rhGH treatment and clinical response (HV and height gain) after 1 and 2 years of treatment. The secondary endpoints included the identification of factors that may affect adherence and, consequently, treatment outcomes.

\section{Methods}

This is a multicentric non-interventional, retrospective observational study. Patients were recruited between February and November 2018. (competitive recruitment) by the pediatric endocrinologists of three Spanish centres: Hospital Miguel Servet (Zaragoza), Consorcio Hospital General Universitario (Valencia) and Hospital de Donosti (San Sebastian).

The patients included were all rhGH-naïve children $(\leq 18$ years) with idiopathic GHD and SGA diagnosis who had been treated with rhGH $\left(\right.$ Saizen $\left.^{\circledR}\right)$ for at least 2 years, with a treatment onset date starting in or after October 2014. Adherence to treatment must have been monitored with EasyPod $^{\mathrm{TM}}$ device with Connect platform. Syndromic patients or those with some associated pathology 
(chromosomopathies, severe inherited cardiomyopathy, severe enterocolitis, brain paralysis, or undergoing cancer treatment) were excluded from the study. Patients or legal guardians were required to sign the informed consent form in order to participate in the study.

Patient data were retrospectively collected by investigators involved in the clinical side of the study in an electronic Case Report Form over the 2-year period. The data collected included:

(1) clinical history (parents' height [cm and SDS], parents' level of education, gestational age [weeks] and weight [kg and SDS] and height [cm and SDS] at birth); (2) demographic and anthropometric characteristics (age [years], sex, weight [kg and SDS], height [cm and SDS], HV [cm/years and SDS], TH [mother's height + father's height) $/ 2 \pm 6.5 \mathrm{~cm},[15], \mathrm{cm}$ and SDS]; height gain [height SDS, calculated according to Spanish standards [16] with height references for healthy Spanish children [17]; Tanner scale scores [18, 19], BA (years) and height prognosis according to Bayley and Pinneau method [20] [cm and SDS]), (3) clinical and treatment characteristics (dose of $\mathrm{GH}$ [mg], treatment indication [GHD or SGA] and maximum level of $\mathrm{GH}$ [ng/ml], and adverse events [AEs, summarized presenting the number of events, the number of subjects, and percentage]), (4) laboratory parameters (efficacy assessments; insulin-like growth factor-1 (IGF-1) levels [ng/ml], IGF-BP3 [mcg/ml]and maximum GH peak $[\mathrm{ng} / \mathrm{ml}]$ ), and (5) reported adherence (percentage of daily adherence recorded by the injection device [EasyPod $^{\mathrm{TM}}$ device with Connect platform]: number of injections received divided by the number of prescribed injections multiplied by 100 , during the period of the study [1 or 2 years]). Information was obtained at start treatment (treatment prescription) and from each yearly visit ( 1 and 2 years after start treatment). Parents educational level was included (none, primary education, secondary education, pre university, formative cycle, university, post-grade).

\section{Study size}

The sample size required was determined by a two-tailed significance of 5, 80\% power, and an assumed 1.5 population standard variation, considering that data were incomplete for up to $10 \%$ of patients; it was 100 subjects.

\section{Statistical methods}

The statistical study was carried out jointly and separating (GDH and SGA) although the results obtained have been very similar. This is because the results regarding growth are similar during the first 2 years.

Patients were classified as GHD or SGA for subgroup analyses. The adherence analysis included two preestablished categories of adherence: optimal $(\geq 85 \%)$ and suboptimal $(<85 \%)$ according the number of doses received in relation to the number of doses programmed [8].

Responses to the rhGH treatment in the first 2 years were measured in terms of: (1) change in height SDS ( $\Delta$ HSDS) in the first and second year, as well as in both years combined, and (2) index of responsiveness (IoR) [21], a parameter that compares the observed first year $\mathrm{HV}$ to a predicted $\mathrm{HV}$ derived from prediction models [22], in the first and second year, where: $\mathrm{IoR} 1=(\mathrm{HV}$ first year $-[12.41-0.36 \times$ age at start $\mathrm{GH}+0.47 \times$ birth weight $\mathrm{SDS}+1.54 \times(\log [3 \times \mathrm{GH}$ dose at start $\mathrm{GH}(\mathrm{mg} / \mathrm{kg} /$ week $)])-0.6 \times[$ HSDS 1 year $-\mathrm{TH}$ $\mathrm{SDS}]+0.28 \times$ weight $\mathrm{SDS} 1$ year $) / 1.72$; and $\mathrm{IoR} 2=(\mathrm{HV}$ second year $-[5.69-0.09 \times$ age at start $\mathrm{GH}+0.63 \times(\log$ $[3 \times \mathrm{GH}$ dose at start $\mathrm{GH}(\mathrm{mg} / \mathrm{kg} / \mathrm{wk})])+0.24 \times$ weight SDS 2 year $+0.31 \times \mathrm{HV}$ first year $) / 1.19$.

Height gain $>0.3 \mathrm{SDS},>0.5 \mathrm{SDS}$, or $\mathrm{HV}>1 \mathrm{SDS}$ or $\Delta$ $\mathrm{HV}>3 \mathrm{~cm} /$ year during the first year were evaluated for analyzing the good response factors in the first year [23].

The association between the continuous measure of adherence at the 2-year point and clinical continuous or discrete parameters was analyzed based on a correlation analysis using the Pearson and Spearman methods.

The comparison between adherence after 2 years $(\geq 85 \%$ vs. $<85 \%$ ) with categorical clinical parameters (yes/no) was evaluated using the Chi-squared test. Only three patients went from Tanner stage 1-2 and one patient from 2 to 3, so no differential study of their growth has been carried out.

The asymptomatic method was applied to estimate the 95\% confidence interval (CI). The comparison between adherence (2 years) and clinical continuous and discrete parameters, as well as the comparison between clinical parameters (yes/no) and the continuous measure of adherence, were later subjected to the Mann-Whitney $U$ test and the $T$-test. Satterthwaite approximation was used in the $T$ test if unequal variances were stated based on the $F$-test. Two-sided $P$ values were obtained and statistically significant results were declared if $p<0.05$. The 95\% CI for the mean difference was based on an asymptotic method. The $95 \%$ CI for the median difference was based on the Hodges-Lehmann method.

Predictive models for the HV and height gain (SDS) as well as dependent variables (based on multiple regression model adjusted by potential prognostic variables [weight and size at birth, sex, TH, parents educational level, maximum level of GH, IGF-1, and IGF-BP3 levels, age at start of therapy, pubertal stage, BA, pretreatment, first and second year HV, rhGH dose, TH, weight, height, adherence...]) were generated using general linear models. Bonferroni multiple test has been used for multiple comparison.

Prognostic analyses were performed after a backward stepwise selection of factors in the complete model. The selection criterion was based on adjusted R2, also taking into account the sample size and the number of parameters 
Fig. 1 Flow chart of the study population selection

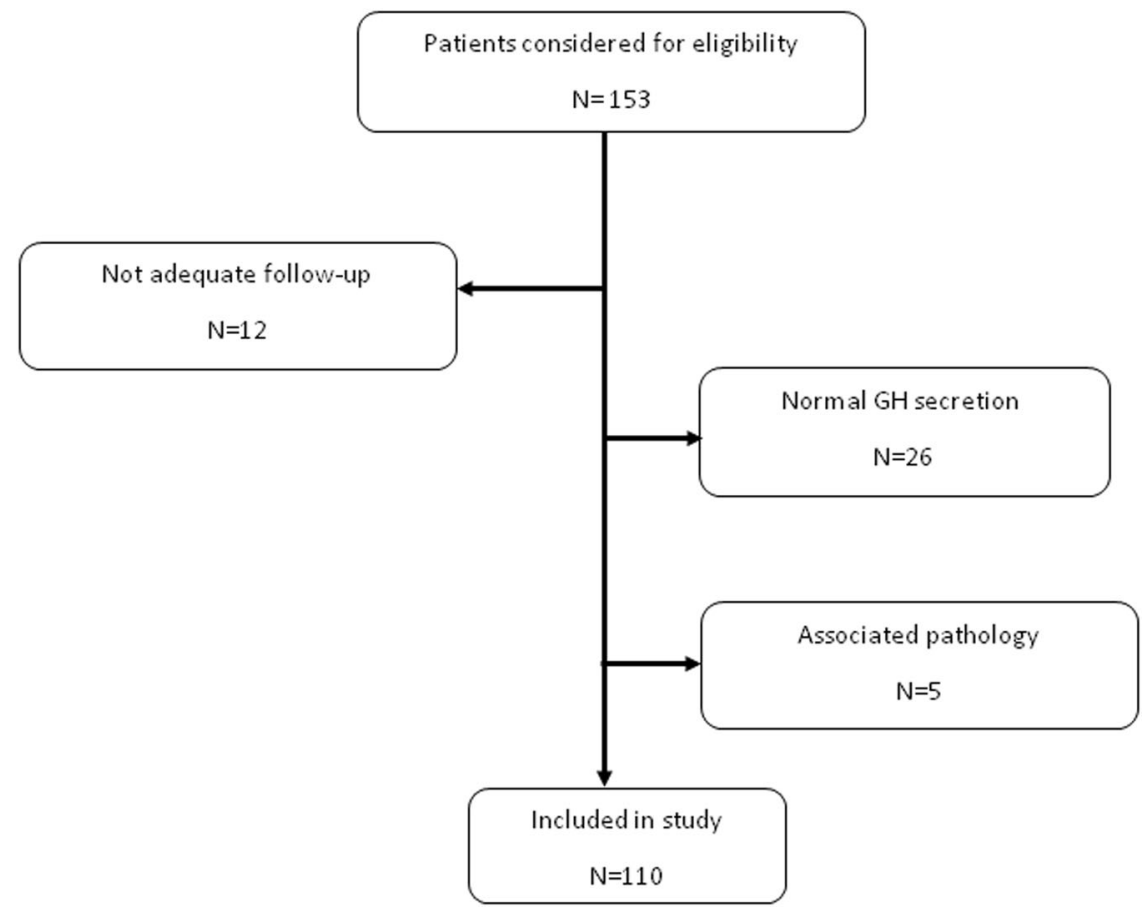

established within the model. The model with the highest adjusted R2 was selected. Following residual test and diagnostic plot assessments, the assumption of multiple regression model was selected.

The highest adjusted R-squared value, determined using the stepwise technique, was the statistical test applied to choose the best model.

\section{Ethics and regulatory approval}

The study was carried out in compliance with the requirements established by the Spanish Agency of Medicines and Medical Products (in Spanish: Agencia Española de Medicamentos y Productos Sanitarios, or AEMPS). AEMPS classified the study as an Observational Post-Authorization Study-Other Design and therefore, it only needed to be approved by a single ethics committee.

All patients provided written informed consent to participate in the study (by parents or legal guardians). Mature children ( $\geq 12$ years) participating in the study were also asked to provide written informed assent. The procedures were carried out in accordance with the Declaration of Helsinki and approved by an independent ethic committee (Comité Ético de Investigación Clínica de Aragón, Spain).

\section{Results}

A total of 153 subjects were included, but 43 patients were excluded from the analysis because they did not meet the eligibility criteria (Fig. 1). Baseline characteristics (sociodemographic and auxological data) may be observed in Table 1 .

Only one subject had medical history data: hypothyroidism treated orally with levothyroxine. The educational level of the father or the mother was available in 74 and 75 subjects, respectively. In 9.5 and $13.3 \%$ of the cases the parent had completed secondary education or less. The pretreatment HV (HV0) and height gain are shown in Table 2 .

All patients have completed 2 years of treatment. Quantitative adherence was very high throughout the study first and second year (Table 2). The adherence was $>95 \%$ in 75.5 and $68.2 \%$ of patients during the first and second year, respectively. In qualitative terms, the adherence was $93.6 \%$ during the first year and $89 \%$ during the second year.

\section{At the start of the $\mathrm{GH}$ treatment}

The age at the start of the $\mathrm{GH}$ treatment was positively correlated with pretreatment height (SDS) $(r=0.485, p<$ $0.0001)$ and weight $\operatorname{SDS}(r=0.352, p<0.001)$ and negatively correlated with the pretreatment $\mathrm{HV}(r=-0.327, p<$ $0.0001), \mathrm{CA} / \mathrm{BA}$ rate $(r=-0.366, p<0.0001)$, and $\Delta$ $\operatorname{HSDS}(r=-0.370, p<0.0001)$.

\section{First year of rhGH treatment}

During the first year, mean adherence was $95.6 \pm 5.73 \%$ (66-100\%). GHD vs. SGA did not make a difference to 
Table 1 Patients' baseline characteristics $(n=110)$

\begin{tabular}{|c|c|c|c|c|c|c|c|c|c|c|c|c|}
\hline & \multicolumn{4}{|c|}{ Overall $(n=110)$} & \multicolumn{4}{|c|}{ GHD $(n=76)$} & \multicolumn{4}{|c|}{ SGA $(n=34)$} \\
\hline Gender-male, $n(\%)$ & \multicolumn{4}{|c|}{$57(51.8)$} & \multicolumn{4}{|c|}{$39(51.3)$} & \multicolumn{4}{|c|}{$18(52.9)$} \\
\hline Age, mean, years $\pm S D$ & \multicolumn{4}{|c|}{$8.5 \pm 3.8$} & \multicolumn{4}{|c|}{$8.9 \pm 3.6$} & \multicolumn{4}{|c|}{$6.5 \pm 3.9$} \\
\hline Range (years) (min-max) & \multicolumn{4}{|c|}{$1.3-15.315 .3$} & \multicolumn{4}{|c|}{$1.3-15.3$} & \multicolumn{4}{|c|}{$4.2-10.6$} \\
\hline \multicolumn{13}{|l|}{ Tanner stage, $n(\%)$} \\
\hline I & \multicolumn{4}{|c|}{$91(82.7)$} & \multicolumn{4}{|c|}{$61(80.3)$} & \multicolumn{4}{|c|}{$30(88.3)$} \\
\hline II & \multicolumn{4}{|c|}{$15(13.6)$} & \multicolumn{4}{|c|}{$11(14.5)$} & \multicolumn{4}{|c|}{$4(11.7)$} \\
\hline III & \multicolumn{4}{|l|}{$2(1.8)$} & \multicolumn{8}{|l|}{$2(2.6)$} \\
\hline IV & \multicolumn{4}{|l|}{$1(0.9)$} & \multicolumn{8}{|l|}{$1(1.3)$} \\
\hline \multirow[t]{2}{*}{$\mathrm{V}$} & \multicolumn{4}{|l|}{$1(0.9)$} & \multicolumn{8}{|l|}{$1(1.3)$} \\
\hline & Mean & SD & Min. & Max. & Mean & SD & Min. & Max. & Mean & $\mathrm{SD}$ & Min. & Max. \\
\hline Father height, $\mathrm{cm}$ & 171.4 & 6.21 & 159.2 & 190.0 & 171.4 & 5.5 & 161.0 & 190.0 & 171.3 & 7.1 & 159.2 & 188.0 \\
\hline SDS & -0.9 & 1.0 & -2.8 & 2.0 & -0.9 & 0.8 & -2.6 & 2.0 & -0.9 & 1.1 & -2.8 & 1.7 \\
\hline Mother height, $\mathrm{cm}$ & 157.4 & 5.8 & 135.8 & 173.7 & 157.1 & 4.9 & 139.0 & 173.7 & 157.7 & 6.8 & 135.8 & 170.0 \\
\hline SDS & -1.1 & 1.0 & -4.7 & 1.6 & -1.1 & 0.8 & -4.2 & 1.6 & -1.1 & 1.1 & -4.7 & 1.0 \\
\hline Target height, SDS & -1.0 & 0.7 & -2.9 & 1.4 & -1.0 & 0.7 & -2.8 & 1.1 & -1.0 & 0.8 & -2.9 & 1.4 \\
\hline Men, cm & 169.9 & 6.4 & 164.1 & 179.0 & 170.5 & 5.4 & 164.4 & 179.0 & 169.5 & 6.0 & 164.1 & 178.8 \\
\hline Women, cm & 158.8 & 5.9 & 147.4 & 172.5 & 158.5 & 5.8 & 147.7 & 172.5 & 159.3 & 5.5 & 147.4 & 171.9 \\
\hline Gestational age & 38.4 & 2.8 & 27.0 & 42.0 & 38.8 & 2.4 & 31.0 & 41.0 & 37.8 & 3.1 & 27.0 & 42.0 \\
\hline Weight at birth,kg & 2.6 & 0.7 & 0.57 & 3.8 & 2.8 & 0.5 & 1.2 & 3.8 & 2.2 & 0.6 & 0.57 & 3.5 \\
\hline SDS & -1.2 & 1.0 & -3.54 & 1.4 & -0.6 & 0.8 & -1.8 & 1.4 & -2.0 & 0.8 & -3.54 & 0.1 \\
\hline Size at birth, $\mathrm{cm}$ & 46.3 & 3.9 & 28.0 & 52.0 & 48 & 2.7 & 39.0 & 52.0 & 44.1 & 4.0 & 28.0 & 49.0 \\
\hline SDS & -1.4 & 1.2 & -4.8 & 1.5 & -0.5 & 0.6 & -1.7 & 1.5 & -2.5 & 0.8 & -4.8 & -0.2 \\
\hline GH peak upon stimulation, $\mathrm{ng} / \mathrm{ml}$ & & & & & 5.3 & 2.5 & 0.7 & & & & & \\
\hline
\end{tabular}

$G H$ growth hormone, $G D H$ GH deficiency, $S D$ standard deviation, $S D S$ SD score, $S G A$ small for gestational age

adherence. At the end of the first year of treatment, the absolute increment of HV was 4.42 SDS (SDS; HV0: -2.04, HV in the first year (HV1): 2.38) (Table 2; Fig. 2).

The $\Delta$ HSDS was 0.57 SDS (21.1\% increase) (Table 2; Fig. 2).

CA/BA ratio was not different between baseline and after the first year of treatment (Table 2).

The height SDS observed at the rhGH onset showed a negative correlation with the dose of rhGH $(r=-0.235$, $p=0.014)$. On the other hand, it had a positive association with the height SDS $(r=0.795, p<0.0001)$, weight SDS $(r=0.371, p<0.0001)$, and height prognosis $(r=0.258$, $p=0.027)$ after 1 year of treatment.

Adherence during the first year was better in younger patients (both at the start of the rhGH treatment $[r=-0.24$, $p=0.009]$ and at year $1[r=-0.25, p=0.008])$, and also in those patients with lower HV0 (SDS) $(r=-0.230, p=$ $0.017)$ and higher HV1 (cm/year, $r=0.33, p=0.01$ and SDS, $r=0.26, p=0.006$ ). Patients with better adherence consistently, showed higher HV1-HV0 $(r=0.182, p=$ 0.04 ). The lower the HVO (SDS), the greater the variation in HV (HV0-HV1) $(r=-0.499), p=<0.001$.

Height gain (SDS) $(r=0.26, p=0.006)$ during the first year and parents' educational level (mother: $r=0.21, p=$
0.04; and father, $r=0.031, p=0.006$ ) showed a positive correlation with the adherence during the first year.

Analyzing the good response factors in the first year, there were no differences in the adherence (mean) in the subgroups of patients with either height gain $>0.3$ SDS or $>0.5 \mathrm{SDS}$, or with $\mathrm{HV}>1 \mathrm{SDS}$ or $\Delta \mathrm{HV}>3 \mathrm{~cm} /$ year during the first year (Table 3). However, among patients with adherence $>90 \%$, the frequency of HV $>1 \mathrm{SD}$ was higher $(p=0.025)$.

\section{Second year of rhGH treatment}

Adherence during the second year of treatment was still high $(93.6 ; 68-100 \%)$. GHD vs. SGA did not make a difference to adherence. The group with optimal adherence (Table 4) showed higher HV in the second year (HV2) $(\mathrm{cm} /$ year). Both groups (adherence $\geq 85$ and $<85 \%$ ) are similar in terms of pubertal development.

At the end of the second year of treatment, the absolute increase of HV from the rhGH onset was 3.94 SDS (Table 2; Fig. 2). Total height gain was 0.99 SDS (a $37.4 \%$ increase) (Table 2; Fig. 2).

Height and weight gain SDS between the first and second year were 0.43 and 0.2 SD, respectively (Table 2; Fig. 2) 
Table 2 Auxological variables along the study period

\begin{tabular}{|c|c|c|c|c|c|c|c|c|c|c|c|c|}
\hline & Basal (At & art rhGH) & & & At year 1 & & & & At year 2 & & & \\
\hline$n=110$ & Mean & SD & Min. & Max. & Mean & SD & Min. & Max. & Mean & SD & Min. & Max. \\
\hline \multicolumn{13}{|l|}{ All patients } \\
\hline Years & 8.5 & 3.8 & 1.3 & 15.3 & 9.5 & 3.8 & 2.2 & 16.2 & 10.5 & 3.8 & 3.2 & 17.2 \\
\hline rhGH dose, $\mathrm{mg} / \mathrm{kg} / \mathrm{day}$ & 0.03 & 0.01 & 0.02 & 0.05 & 0.03 & 0.00 & 0.02 & 0.05 & 0.03 & 0.01 & 0.02 & 0.06 \\
\hline Weight, SDS & -1.6 & 0.6 & -3.4 & -0.2 & -1.3 & 0.5 & -2.5 & 0.7 & -1.1 & 0.6 & -2.2 & 0.9 \\
\hline Height, SDS & -2.6 & 0.5 & -4.4 & -1.6 & -2.1 & 0.6 & -3.8 & -0.9 & -1.7 & 0.6 & -3.5 & -0.1 \\
\hline Height velocity, $\mathrm{cm} /$ year & 4.5 & 1.1 & 1.9 & 7.1 & 8.6 & 1.7 & 3.4 & 14.0 & 7.4 & 1.6 & 0.7 & 11.6 \\
\hline SDS & -2.0 & 0.9 & -4.7 & -0.8 & 2.4 & 1.7 & -2.0 & 10.7 & 1.9 & 1.8 & -1.3 & 8.5 \\
\hline Height gain, SDS & -0.2 & 0.3 & -2.0 & 0.8 & 0.6 & 0.3 & -0.2 & 2.0 & 0.4 & 0.3 & -0.3 & 1.6 \\
\hline Bone age, years & 7.2 & 3.7 & 1.0 & 13.5 & 8.4 & 3.7 & 1.5 & 14.5 & 9.6 & 3.7 & 3.5 & 15.7 \\
\hline $\mathrm{CA} / \mathrm{BA}$ & 1.2 & 0.2 & 0.9 & 2.1 & 1.2 & 0.2 & 0.9 & 1.7 & 1.1 & 0.11 & 0.88 & 1.5 \\
\hline \multicolumn{13}{|l|}{ Height prognosis, mean, $\mathrm{cm}$} \\
\hline Men $(n=57)$ & 162.4 & 7.5 & 158.2 & 184.1 & 165.1 & 7.7 & 161.2 & 188.1 & 166.8 & 7.2 & 163.7 & 195.7 \\
\hline Woman $(n=53)$ & 148.3 & 6.6 & 140.3 & 155.8 & 152.5 & 6.5 & 143 & 163.2 & 154.8 & 6.8 & 142 & 166.1 \\
\hline IGF-I, ng/ml & 133.5 & 84.6 & 5.0 & 381.8 & 310.7 & 172.9 & 48.1 & 808.3 & 332.5 & 174.3 & 42.7 & 849.4 \\
\hline IGF-BP3, $\mathrm{mcg} / \mathrm{ml}$ & 3.6 & 1.2 & 0.6 & 6.3 & 5.2 & 1.3 & 2.2 & 8.6 & 5.7 & 1.6 & 2.5 & 9.4 \\
\hline Adherence, \% & NA & NA & NA & NA & 95.6 & 5.7 & 66.0 & 100.0 & 94.0 & 7.6 & 68.0 & 100.0 \\
\hline IoR & NA & NA & NA & NA & -0.1 & 1.3 & -2.9 & 3.5 & 0.2 & 1.2 & -3.9 & 3.9 \\
\hline \multicolumn{13}{|l|}{$n=76$} \\
\hline \multicolumn{13}{|l|}{ GHD } \\
\hline Age, years & 8.9 & 3.6 & 1.3 & 15.3 & 9.9 & 3.4 & 2.2 & 16.2 & 10.9 & 3.7 & 3.2 & 17.2 \\
\hline rhGH dose, $\mathrm{mg} / \mathrm{kg} /$ day & 0.03 & 0.02 & 0.02 & 0.03 & 0.03 & 0.02 & 0.02 & 0.04 & 0.03 & 0.02 & 0.02 & 0.04 \\
\hline Weight, SDS & -1.8 & 0.7 & -2.9 & -0.2 & -1.2 & 0.5 & -2.4 & 0.7 & -1.1 & 0.6 & -1.7 & 0.9 \\
\hline Height, SDS & -2.4 & 0.4 & -3.2 & -1.6 & -1.9 & 0.6 & -2.9 & -0.9 & -1.5 & 0.6 & -2.5 & -0.1 \\
\hline Height velocity, $\mathrm{cm} /$ year & 4.6 & 1.1 & 1.9 & 7.1 & 8.8 & 1.7 & 3.4 & 14.0 & 7.5 & 1.6 & 0.7 & 11.6 \\
\hline SDS & -2.0 & 0.9 & -4.7 & -0.8 & 2.5 & 1.7 & -2.0 & 10.7 & 1.9 & 1.8 & -1.3 & 8.5 \\
\hline Height gain, SDS & -0.2 & 0.3 & -2.0 & 0.8 & 0.6 & 0.3 & -0.2 & 2.0 & 0.4 & 0.3 & -0.3 & 1.6 \\
\hline Bone age, years & 7.4 & 3.5 & 1.0 & 13.5 & 8.4 & 3.7 & 1.5 & 14.5 & 9.5 & 3.7 & 3.5 & 15.7 \\
\hline $\mathrm{CA} / \mathrm{BA}$ & 1.2 & 0.2 & 0.9 & 2.1 & 1.2 & 0.2 & 0.9 & 1.7 & 1.1 & 0.11 & 0.9 & 1.5 \\
\hline \multicolumn{13}{|l|}{ Height prognosis, mean, $\mathrm{cm}$} \\
\hline Men $(n=39)$ & 161.5 & 7.7 & 158.2 & 174.1 & 164.2 & 7.3 & 161.2 & 176.1 & 165.8 & 7.2 & 163.7 & 179.7 \\
\hline Woman $(n=37)$ & 148.2 & 6.6 & 140.3 & 154.5 & 152.4 & 5.4 & 143 & 159.3 & 154.7 & 6.8 & 142 & 165.7 \\
\hline IGF-I, ng/ml & 129.4 & 81.2 & 5.0 & 381.8 & 301.2 & 199.9 & 48.1 & 808.3 & 342.7 & 224.3 & 42.7 & 849.4 \\
\hline IGF-BP3, $\mathrm{mcg} / \mathrm{ml}$ & 3.5 & 1.6 & 0.6 & 5.3 & 5.1 & 1.3 & 2.2 & 8.6 & 5.7 & 1.6 & 2.5 & 9.4 \\
\hline Adherence, $\%$ & NA & NA & NA & NA & 95.7 & 5.7 & 66.0 & 100.0 & 94.0 & 7.6 & 68.0 & 100.0 \\
\hline IoR & NA & NA & $\mathrm{NA}$ & NA & -0.1 & 1.3 & -2.7 & 3.5 & 0.2 & 1.2 & -3.9 & 3.9 \\
\hline \multicolumn{13}{|l|}{$n=34$} \\
\hline \multicolumn{13}{|l|}{ SGA } \\
\hline Age, years & 6.5 & 3.9 & 4.2 & 10.6 & 7.5 & 3.8 & 5.2 & 11.6 & 8.5 & 3.6 & 6.2 & 12.6 \\
\hline rhGH dose, $\mathrm{mg} / \mathrm{kg} / \mathrm{day}$ & 0.03 & 0.02 & 0.03 & 0.05 & 0.03 & 0.02 & 0.03 & 0.05 & 0.03 & 0.02 & 0.02 & 0.06 \\
\hline Weight, SDS & -1.5 & 0.6 & -3.4 & -1.2 & -1.3 & 0.5 & -2.5 & -0.2 & -1.1 & 0.6 & -2.2 & 0.4 \\
\hline Height, SDS & -3.0 & 0.6 & -4.4 & -2.0 & -2.4 & 0.7 & -3.8 & -1.1 & -1.9 & 0.5 & -3.5 & -0.7 \\
\hline Height velocity, $\mathrm{cm} /$ year & 4.4 & 1.0 & 3.1 & 5.4 & 8.5 & 1.7 & 5.4 & 10.4 & 7.4 & 1.6 & 6.1 & 9.6 \\
\hline SDS & -1.9 & 0.9 & -2.9 & -0.9 & 2.3 & 1.7 & -1.8 & 8.1 & 2.0 & 1.8 & -0.5 & 6.5 \\
\hline Height gain, SDS & -0.2 & 0.3 & -2.0 & 0.8 & 0.6 & 0.3 & 0.0 & 1.9 & 0.4 & 0.3 & 0.0 & 1.5 \\
\hline Bone age, years & 5.1 & 2.7 & 3.0 & 9.5 & 6.3 & 3.1 & 4.0 & 10.5 & 7.4 & 3.5 & 5.0 & 11.5 \\
\hline $\mathrm{CA} / \mathrm{BA}$ & 1.3 & 0.2 & 0.8 & 2.1 & 1.2 & 0.2 & 0.9 & 1.6 & 1.11 & 0.11 & 0.88 & 1.4 \\
\hline \multicolumn{13}{|l|}{ Height prognosis, mean, $\mathrm{cm}$} \\
\hline Men $(n=18)$ & 164.1 & 7.2 & 159.1 & 184.1 & 166.8 & 7.9 & 161.9 & 188.1 & 167.4 & 7.4 & 163.7 & 195.7 \\
\hline Woman $(n=16)$ & 148.5 & 6.6 & 141.3 & 155.8 & 152.5 & 6.5 & 143.4 & 163.2 & 154.8 & 6.8 & 142.6 & 166.1 \\
\hline IGF-I, ng/ml & 136.8 & 85.5 & 75 & 352.3 & 322.9 & 166.5 & 137.5 & 522.6 & 327.3 & 144.3 & 150.7 & 559.4 \\
\hline IGF-BP3, $\mathrm{mcg} / \mathrm{ml}$ & 3.6 & 1.1 & 1.6 & 6.3 & 5.2 & 1.1 & 2.2 & 6.6 & 5.7 & 1.5 & 2.5 & 7.1 \\
\hline Adherence, $\%$ & NA & NA & NA & NA & 95.6 & 5.7 & 68.0 & 100.0 & 94.1 & 7.6 & 69.0 & 100.0 \\
\hline IoR & NA & NA & NA & NA & -0.1 & 1.2 & -2.9 & 3.1 & 0.2 & 1.3 & -3.5 & 3.7 \\
\hline
\end{tabular}

$B A$ bone age, $C A$ chronological age, $G H D$ growth hormone deficiency, $I G F-1$ insulin-like growth factor-1, IGF-BP3 IGF binding protein-3, IoR index of responsiveness, Max. maximum, Min. minimum, $r h G H$ recombinant human growth hormone, $S D$ standard deviation, $S D S$ standard deviation score, $S G A$ small for gestational age 


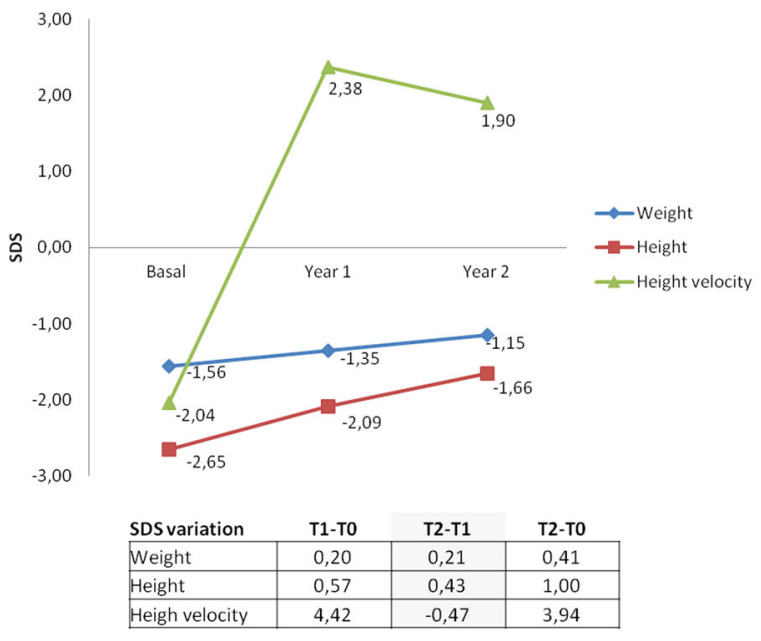

Key: SDS: Standard deviation score; TO: rhGH treatment onset (basal situation); $\mathrm{T} 1$ : year 1; T2: year 2.

Fig. 2 Weight, height, and height velocity (SDS) variation during rhGH treatment

The rhGH dose in the second year was higher in those patients who had lower values of IoR1 $(r=-0.423, p=$ $0.000)$, height SDS $(r=-0.397, p=0.000)$, HV SDS $(r=$ $-0.218, p=0.022)$, and HV1-HV0 $(r=-0.211, p=$ $0.027)$ at year 1 .

Height SDS at year 2 has a positive association with the height SDS at year $1(r=0.887, p=0.000)$, the IoR $1(r=$ $0581, p=0.000)$, and the IoR2 $(r=0201, p=0.035)$.

Patients with the highest IoR2 showed the best adherence during the first and second year $(r=0.246, p=0.01$, and $r=0.298, p=0.002$, respectively).

Adherence during the second year was higher among younger children (both at the beginning and at year 2: $r=$ $-0.28, p=0.00$, and $r=-0.287, p=<0.01$, respectively) and among children with better adherence in the first year $(r=0.836, p=<0.001)$. In addition, adherence showed a direct correlation with HV1-HV0 $(r=0.201, p=0.035)$ and HV2 $(r=0.34, p=0.00)$, as well as with the parents' educational level (mother: $r=0.24, p=0.03$; and father, $r=0.35, p=0.00$ ).

\section{Height velocity after 2 years}

Both in SGA and GHD children, HV (cm/year and SDS) was higher in those patients with a higher adherence percentage $(p=0.03)$.

At year 2, HV was higher in those patients with adherence $>85$ vs. $<85 \%(7.6 \pm 1.61$ vs. $6.1 \pm 1.34 \mathrm{~cm} /$ year, $p=$ $0.001)$.

A decline of $0.6 \mathrm{~cm} /$ year in HV was observed for every $10 \%$ decrease in adherence in SGA children. For GHD children, the decrease observed was $1.1 \mathrm{~cm} /$ year.

The percentage of adherence (\%) and the Tanner stage reached an adjusted $\mathrm{R}$ squared of 0.263 , and these factors consequently explain $26.3 \%$ of the variability of HV. When this model was used for only GHD children, the adjusted R squared increased to 0.334 and explain $33.4 \%$. This model explains $38.8 \%$ in SGA patients.

\section{Height gain after 2 years}

The height gain after 2 years of treatment was greater in those patients with a higher adherence (\%). For every $10 \%$ decrease in adherence, a decline of $1.8 \mathrm{~cm}$ was observed.

Subjects with a higher dose of rhGH show greater height gain after 2 years of treatment. Starting the treatment before the onset of puberty was also associated with a greater height gain of $2.5 \mathrm{~cm}$.

The best fit model for the whole sample to predict height gain $(\mathrm{cm})$ reached an adjusted $\mathrm{R}$ squared of 0.388 and was made up with the following independent variables: pretreatment HV, Tanner stage, percentage of adherence to the $\mathrm{rhGH}$, baseline BA, and gestational age.

In the case of children with GHD, the best fit model to predict the height gain in $\mathrm{cm}$ reached an adjusted R-squared of 0.489 and was made up with the following factors: percentage of adherence, the Tanner stage, the baseline HV, the dose of rhGH and whether the treatment was initiated before or after puberty.

Nothing found for SGA children in this model.

\section{Safety}

A total of 110 subjects were assessed. There was only one adverse event (AE) in one patient (0.9\%) —one AE each: an Osgood-Schlater disease. It was considered as unlikely related to the treatment. No serious AEs or deaths have been reported.

\section{Discussion}

Adherence to $\mathrm{GH}$ treatment is an extremely significant determinant of its success [24, 25]. In our study of rhGHnaïve children treated with $\mathrm{GH}$ (Easypod $^{\mathrm{TM}}$ electronic device with Connect platform) $(n=110)$, a $10 \%$ reduction in adherence during the first 2 years was correlated with a decrease of $1.1 \mathrm{~cm} /$ year in $\mathrm{HV}$.

Overall, patients reached a good mean level of adherence after only 1 year of rhGH treatment $(95.64 \%)$, and decreased slightly after 2 years $(93.98 \%)$. These values are very similar to the mean adherence rate observed in the Spanish cohort $(n=238)$ from the ECOS study [8], which showed $95.3 \%$ adherence at year 1 and $93.7 \%$ at year 2 .

We observed almost the same percentages of adherence in SGA and GDH population at 1 year $(95.6 \%$ and $95.7 \%$, respectively) and 2 years ( $94.1 \%$ and $94.0 \%$, respectively). 
Table 3 Adherence and measurements of efficacy in different subgroups of patients based on the results reached during the first year of rhGH treatment

\begin{tabular}{|c|c|c|c|c|c|c|c|c|}
\hline & \multicolumn{2}{|c|}{ Height gain $>0.3 \mathrm{SD}$} & \multicolumn{2}{|c|}{ Height gain $>0.5 \mathrm{SD}$} & \multicolumn{2}{|l|}{$\mathrm{HV}>1 \mathrm{SD}$} & \multicolumn{2}{|c|}{$\Delta \mathrm{HV}>3 \mathrm{~cm} /$ year } \\
\hline & Yes $n=95$ & No $n=15$ & Yes $n=59$ & No $n=51$ & Yes $n=90$ & No $n=20$ & Yes $n=78$ & No $n=32$ \\
\hline \multicolumn{9}{|c|}{ Adherence \% } \\
\hline Mean & 95.92 & 93.87 & 95.86 & 95.37 & 96.03 & 93.85 & 95.15 & 94.32 \\
\hline SD & 5.6 & 6.09 & 6.25 & 5.12 & 5.40 & 6.92 & 4.96 & 7.23 \\
\hline SE mean & 0.58 & 1.57 & 0.81 & 0.72 & 0.57 & 1.55 & 0.56 & 1,28 \\
\hline & \multicolumn{2}{|l|}{ No difference } & \multicolumn{2}{|l|}{ No difference } & \multicolumn{2}{|l|}{ No difference } & \multicolumn{2}{|l|}{ No difference } \\
\hline \multicolumn{9}{|c|}{ Height SDS } \\
\hline Mean & -2.02 & -2.47 & -1.89 & -2.31 & -2.01 & -2.42 & -1.93 & -2.45 \\
\hline SD & 0.56 & 0.54 & 0.55 & 0.52 & 0.54 & 0.61 & 0.50 & 0.57 \\
\hline SE mean & $\begin{array}{c}0.06 \\
p=0.005\end{array}$ & 0.14 & $\begin{array}{c}0.07 \\
p<0.0100\end{array}$ & 0.07 & $\begin{array}{c}0.06 \\
p=0.003\end{array}$ & 0.14 & $\begin{array}{c}0.06 \\
p<0.0100\end{array}$ & 0.10 \\
\hline \multicolumn{9}{|l|}{ HV SDS } \\
\hline Mean & 2.61 & 0.93 & 2.97 & 1.69 & 2.83 & 0.34 & 2.87 & 1.17 \\
\hline SD & 1.73 & 0.77 & 1.80 & 1.38 & 1.56 & 0.69 & 1.71 & 1.06 \\
\hline SE mean & $\begin{array}{c}0.18 \\
p<0.0100\end{array}$ & 0.20 & $\begin{array}{c}0.23 \\
p<0.0100\end{array}$ & 0.19 & $\begin{array}{c}0.16 \\
p<0.0100\end{array}$ & 0.15 & $\begin{array}{c}0.19 \\
p<0.0100\end{array}$ & 0.19 \\
\hline \multicolumn{9}{|c|}{$\Delta$ HSDS, SDS } \\
\hline Mean & 0.65 & 0.14 & 0.79 & 0.32 & 0.63 & 0.35 & 0.63 & 0.44 \\
\hline SD & 0.29 & 0.14 & 0.28 & 0.15 & 0.32 & 0.26 & 0.34 & 0.24 \\
\hline SE mean & $\begin{array}{c}0.03 \\
p<0.0100\end{array}$ & 0.04 & $\begin{array}{c}0.04 \\
p<0.0100\end{array}$ & 0.02 & $\begin{array}{c}0.03 \\
p<0.0100\end{array}$ & 0.06 & $\begin{array}{c}0.04 \\
p=0.005\end{array}$ & 0.04 \\
\hline \multicolumn{9}{|l|}{ HV1-HV0 } \\
\hline Mean & 4.29 & 2.49 & 4.49 & 2.52 & 4.40 & 2.45 & 4.99 & 1.73 \\
\hline SD & 1.91 & 1.99 & 1.94 & 1.99 & 1.87 & 1.91 & 1.49 & 0.97 \\
\hline SE mean & $\begin{array}{c}0.20 \\
p=0.001\end{array}$ & 0.51 & $\begin{array}{c}0.25 \\
p=0.011\end{array}$ & 0.28 & $\begin{array}{c}0.20 \\
p<0.0100\end{array}$ & 0.43 & $\begin{array}{c}0.17 \\
p<0.0100\end{array}$ & 0.17 \\
\hline \multicolumn{9}{|l|}{ IoR } \\
\hline Mean & 0.04 & -0.89 & 0.24 & -0.45 & 0.15 & -1.13 & 0.42 & -1.31 \\
\hline SD & 1.30 & 1.09 & 1.24 & 1.24 & 1.22 & 1.16 & 1.13 & 0.78 \\
\hline SE mean & $\begin{array}{c}0.13 \\
p=0.009\end{array}$ & 0.28 & $\begin{array}{c}0.16 \\
p=0.005\end{array}$ & 0.18 & $\begin{array}{c}0.13 \\
p<0.0100\end{array}$ & 0.26 & $\begin{array}{c}0.13 \\
p<0.0100\end{array}$ & 0.14 \\
\hline
\end{tabular}

$\overline{H V}$ height velocity, $H V O$ basal $\mathrm{HV}, H V 1 \mathrm{HV}$ at year $1, I o R 1$ index of responsiveness at year $1, r h G H$ recombinant human growth hormone, $S D$ standard deviation, SDS standard deviation score, SE standard error, $\triangle H S D S$ change in height SDS

However, in the Spanish cohort of the ECOS study the adherence at first year was higher in the SGA vs. GHD patients ( $97.4 \%$ vs. $93.9 \%$, respectively). In that study, the decrease in the adherence observed at 2 years was greater in the SGA patients; the percentages at that time were of 93.1 and $93.8 \%$ in SGA and GHD and patients, respectively.

These results confirm that there is high adherence in the Spanish population, with higher values of adherence after 1 and 2 years than those observed in the overall population ( $n=608$; excluding Spanish patients) and in the Italian cohort ( $n=73$ ) from the ECOS study: $84.30 \%$ and $81.41 \%$ [24] and $88.5 \%$ and $86.6 \%$ [26], respectively.
Despite the differences observed, all results showed that adherence decreased with increasing treatment duration, unlike what is observed in the Spanish cohort of the ECOS study in which the duration of treatment did not showed significant differences on treatment adherence

Notwithstanding the decrease in adherence after the second year, the high percentage of adherence remained consistently high throughout the treatment in those patients with better responses (i.e., higher HV). A higher percentage of HV $>1$ SDS was observed with adherence $>90 \%$ during the first year and adherence $>85 \%$ during the second year. In the Spanish ECOS study, height 
Table $4 \mathrm{HV}$ (cm/years) during the second year of rhGH treatment based on adherence (optimal $\geq 85 \%$ vs. suboptimal $<85 \%$ )

\begin{tabular}{llll}
\hline HV & Adherence $\geq 85 \%$ & Adherence $<85 \%$ & $p$ \\
\hline All patients & & & \\
$n$ & 98 & 12 & 0.002 \\
Mean & 7.60 & 6.10 & \\
SD & 1.61 & 1.34 & 0.001 \\
Median & 7.60 & 6.10 & \\
Min-max & $0.7-11.6$ & $4.0-8.4$ & \\
GHD patients & & & 0.002 \\
$n$ & 69 & 7 & 0.001 \\
Mean & 7.69 & 6.2 & \\
SD & 1.65 & 1.4 & \\
Median & 7.69 & 6.2 & 0.002 \\
Min-max & $0.7-11.6$ & $4.0-7.2$ & \\
SGA patients & & & 0.001 \\
$n$ & 29 & 5 & \\
Mean & 7.55 & 6.05 & \\
SD & 1.11 & 6.05 & \\
Median & 7.55 & $4.5-8.4$ & \\
Min-max & $6.1-9.6$ & & \\
\hline
\end{tabular}

$H V$ height velocity, $r h G H$ recombinant human growth hormone, $S D$ standard deviation

(SDS) was also higher with adherence $>85 \%$ after 3 years of treatment [8].

In qualitative terms, adherence is considered "optimal" when it is $85 \%$ or higher, and "suboptimal" if it is lower than $85 \%$ (this threshold corresponds to adherence 6 out of 7 days). When adherence is considered in these terms, the only correlation that is statistically significant is in relation to the HV (expressed in cm/year, but not in SDS) in the second year of treatment. This seems to indicate that, within this sample of highly compliant subjects, the prespecified threshold was not sensitive enough.

Nonadherence to rhGH treatment impacts growth response [27]. Consistently, and in concordance with the results of the ECOS study [8, 24], patients with a higher adherence rate during 2 years showed higher $\mathrm{HV}(\mathrm{cm} /$ year and SDS), and therefore greater height gain (SDS). This was despite the little variation in adherence at the high extreme (above 90\%).

In the first year of $\mathrm{GH}$ treatment, patients showed a marked improvement in all of the main auxological variables that were assessed: HV and height gain. The rhGH dose in the second year was higher in those patients who had lower values of IoR1, height SDS, HV SDS, and HV1HV0 at year 1; perhaps it reflects proactive management applied in these patients group based on IoR and adherence.

Our results showed that at least 2 years of rhGH treatment are required to accelerate the increase in $\mathrm{BA}$ and to observe a normalization of the BA in relation to CA. This finding was previously observed in a randomized controlled study using a similar rhGH dosage during 1 year [28]; after the first year there was no difference in BA between untreated and treated children. Furthermore, a recent analysis of data regarding prepubertal children with idiopathic GH deficiency and idiopathic short stature treated with rhGH over 3 years, also showed significant BA-CA changes in the second year of treatment [29].

When considering the information presented above, it becomes apparent that the importance of adherence in the second year of treatment must be assessed and demonstrated, because that's when it starts to decrease. In cases where adherence shows insufficient variation (as is suspected with the use of electronic administering devices, and when prescriptions are more recent), the assessment becomes even more complex, further demonstrating the need for adherence to be explored and examined [9].

In addition to the duration of treatment, other factors showed a negative correlation with the adherence, such as pretreatment HV. This could be justified by the fact that low HV could raise awareness of the need for treatment and its benefits, and thereby influence adherence [27]. Patients that fit this category show the greatest improvement in HV during the first year, which confirms the impact of adherence on response to rhGH treatment [8].

Furthermore, during the first 2 years of rhGH treatment, and as previously reported, adherence was inversely related to chronological age at initiation of rhGH therapy [25]. This might reflect the known fact that younger age as well as adolescence are associated with a lower adherence to $\mathrm{rhGH}$ treatment [2].

Our results also showed that the education level of the parents was associated with a greater adherence during the first and second year of rhGH treatment. Though this correlation has been previously reported (either with regards to the level of education of the mother, father or both) [30, 31], the evidence has not been consistent [27].

The IoR1 and IoR2 allow for predicted positive responses to $\mathrm{GH}$ treatment. The predictive value of these parameters has been previously described. IoR 1 has shown differences between patients and has been used in predictive models for near final adult height (nFAH) [22]. On the other hand, it is important to note that IoR2 has been shown to be a strong association with adherence during the first and second year [2], although it is not used for its calculation.

One weakness of our study is its retrospective uncontrolled and observational nature. However, by using the electronic device, Easypod ${ }^{\mathrm{TM}}$, we have provided a precise and objective measurement of adherence. This has increased the amount of evidence regarding this available device, yet very scarce. 


\section{Conclusions}

In conclusion, measuring adherence to $\mathrm{GH}$ treatment is essential in determining the effectiveness of the treatment and assessing whether patients will be a good or poor responders. In this study, adherence was very high during the first 2 years of treatment. Although this observation should be taken into account for the correct management of patients, it might hinder our ability to accurately assess the association between this variable and auxological outcomes. Adherence showed a direct correlation with growth outcomes throughout the treatment. It is important to recognize that a $10 \%$ reduction in adherence may cause a decrease of $1.1 \mathrm{~cm} /$ year in HV. Furthermore, our results confirmed that age and pretreatment $\mathrm{HV}$, as well as the duration of the treatment, showed a negative correlation with adherence, whereas there was a positive association between adherence and the education level of the parents. So, we think that it is essential to use devices that allow an adequate assessment of adherence for a better follow-up of patients.

Acknowledgements We thank the parents who consented to their children being enrolled in the study.

Funding This research was sponsored and funded by Merck.

Author contributions All of the authors participated in the design of the study and the review of patients data. AdeAM conducted the statistical side of the study. In addition, every author contributed to the analysis and interpretation of the data and the writing of the report, and all participated in the decision to submit the report for publication.

\section{Compliance with ethical standards}

Conflict of interest The authors declare that they have no conflict of interest.

Consent to participate All patients provided written informed consent to participate in the study (by parents or legal guardians). Mature children ( $\geq 12$ years) participating in the study were also asked to provide written informed assent.

Ethics approval The study was approved by an independent ethic committee (Comité Ético de Investigación Clínica de Aragón, Spain).

Publisher's note Springer Nature remains neutral with regard to jurisdictional claims in published maps and institutional affiliations.

\section{References}

1. A. Carrascosa, D. Yeste, A. Copil, M. Gussinye, Secular growth changes. Weight, height and body mass index values in infant, children, adolescent and young adults from Barcelona population. Med Clin. 123, 445-451 (2004). https://doi.org/10.1016/s00257753(04)74552-2

2. P. van Dommelen, E. Koledova, J.M. Wit, Effect of adherence to growth hormone treatment on 0-2 year catch-up growth in children with growth hormone deficiency. PLoS ONE 13, e0206009 (2018). https://doi.org/10.1371/journal.pone.0206009

3. J.M. Wit, M.B. Ranke, K. Albertsson-Wikland, A. Carrascosa, R. G. Rosenfeld, S. Van Buuren, B. Kristrom, E. Schoenau, L. Audi, A.C. Hokken-Koelega, P. Bang, H. Jung, W.F. Blum, L.A. Silverman, P. Cohen, S. Cianfarani, C. Deal, P.E. Clayton, L. de Graaff, J. Dahlgren, J. Kleintjens, M: Roelants, Personalized approach to growth hormone treatment: clinical use of growth prediction models. Horm. Res. Paediatr. 79, 257-270 (2013). https://doi.org/10.1159/000351025

4. World Health Organization (WHO). Adherence to Long-term Therapies Evidence for Action. Ann Saudi Med. 24:221-222 (2004). https://doi.org/10.5144/0256-4947.2004.221

5. L. Osterberg, T. Blaschke, Adherence to medication. N. Engl. J. Med. 353, 487-497 (2005). https://doi.org/10.1056/NEJMra 050100

6. W.S. Cutfield, J.G. Derraik, A.J. Gunn, K. Reid, T. Delany, E. Robinson, P.L. Hofman, Non-compliance with growth hormone treatment in children is common and impairs linear growth. PLoS One 6, e16223 (2011). https://doi.org/10.1371/journal.pone. 0016223

7. R.R. Kapoor, S.A. Burke, S.E. Sparrow, I.A. Hughes, D.B. Dunger, K.K. Ong, C.L. Acerini, Monitoring of concordance in growth hormone therapy. Arch. Dis. Child 93, 147-148 (2008). https://doi.org/10.1136/adc.2006.114249

8. M.D. Rodriguez Arnao, A. Rodriguez Sanchez, I. Diez Lopez, J. Ramirez Fernandez, J.A. Bermudez de la Vega, D. Yeste Fernandez, M. Chueca Guindulain, R. Corripio Collado, J. Perez Sanchez, A: Fernandez Gonzalez, Adherence and long-term outcomes of growth hormone therapy with easypod in pediatric subjects: Spanish ECOS study. Endocr. Connect 8, 1240-1249 (2019). https://doi.org/10.1530/ec-19-0325

9. M.D. Rodriguez Arnao, A.R. Sanchez, C. Garcia-Rey, F.J. Arroyo Diez, R.C. Estrada, B.G. Cuartero, M.A. Merillas, J.P. LopezSiguero, The DATAC study: a new growth database. Description of the epidemiology, diagnosis and therapeutic attitude in a group of Spanish children with short stature. J. Pediatr. Endocrinol. Metab. 27, 1201-1208 (2014). https://doi.org/10.1515/jpem-20130394

10. M.B. Ranke, A. Lindberg, Observed and predicted total pubertal growth during treatment with growth hormone in adolescents with idiopathic growth hormone deficiency, Turner syndrome, short stature, born small for gestational age and idiopathic short stature: KIGS analysis and review. Horm. Res. Paediatr. 75, 423-432 (2011). https://doi.org/10.1159/000324117

11. E. Schonau, F. Westermann, F. Rauch, A. Stabrey, G. Wassmer, E. Keller, J. Bramswig, W.F. Blum, A new and accurate prediction model for growth response to growth hormone treatment in children with growth hormone deficiency. Eur. J. Endocrinol. 144, 13-20 (2001). https://doi.org/10.1530/eje.0.1440013

12. K.A. Wikland, B. Kristrom, S. Rosberg, B. Svensson, A.F. Nierop, Validated multivariate models predicting the growth response to GH treatment in individual short children with a broad range in GH secretion capacities. Pediatr. Res. 48, 475-484 (2000). https://doi.org/10.1203/00006450-200010000-00010

13. S. Graham, J. Weinman, V. Auyeung, Identifying potentially modifiable factors associated with treatment non-adherence in paediatric growth hormone deficiency: a systematic review. Horm. Res. Paediatr. 90, 221-227 (2018). https://doi.org/10.1159/ 000493211

14. B.K. Aydin, Z. Aycan, Z. Siklar, M. Berberoglu, G. Ocal, S. Cetinkaya, V.N. Bas, H.N. Kendirci, E. Cetinkaya, S. Darcan, D. Goksen, O. Evliyaoglu, M. Sukur, F. Bas, F. Darendeliler, Adherence to growth hormone therapy: results of a multicenter study. Endocr. Pr. 20(1), 46-51 (2014). https://doi.org/10.4158/ ep13194.or 
15. J.M. Tanner, H. Goldstein, R.H. Whitehouse, Standards for children's height at ages 2-9 years allowing for heights of parents. Arch. Dis. Child. 45, 755-762 (1970). https://doi.org/10.1136/adc. 45.244.755

16. A. Carrascosa Lezcano, J.M. Fernandez Garcia, C. Fernandez Ramos, A. Ferrandez Longas, J.P. Lopez-Siguero, E. Sanchez Gonzalez, B. Sobradillo Ruiz, D: Yeste Fernandez, Spanish crosssectional growth study 2008. Part II. Height, weight and body mass index values from birth to adulthood. Pediatrics 68, 552-569 (2008). https://doi.org/10.1157/13123287

17. B.S. Finkelstein, T.F. Imperiale, T. Speroff, U. Marrero, D.J. Radcliffe, L. Cuttler, Effect of growth hormone therapy on height in children with idiopathic short stature: a meta-analysis. Arch. Pediatr. Adolesc. Med. 156, 230-240 (2002). https://doi.org/10. 1001/archpedi.156.3.230

18. W.A. Marshall, J.M. Tanner, Variations in pattern of pubertal changes in girls. Arch. Dis. Child 44, 291-303 (1969). https://doi. org/10.1136/adc.44.235.291

19. W.A. Marshall, J.M. Tanner, Variations in the pattern of pubertal changes in boys. Arch. Dis. Child 45, 13-23 (1970). https://doi. org/10.1136/adc.45.239.13

20. N. Bayley, S.R. Pinneau, Tables for predicting adult height from skeletal age: revised for use with the Greulich-Pyle hand standards. J. Pediatr. 40, 423-441 (1952). https://doi.org/10.1016/ s0022-3476(52)80205-7

21. M.B. Ranke, A. Lindberg, P. Chatelain, P. Wilton, W. Cutfield, K. Albertsson-Wikland, D.A. Price, Derivation and validation of a mathematical model for predicting the response to exogenous recombinant human growth hormone $(\mathrm{GH})$ in prepubertal children with idiopathic GH deficiency. KIGS International Board. Kabi Pharmacia International Growth Study. J. Clin. Endocrinol. Metab. 84, 1174-1183 (1999). https://doi.org/10.1210/jcem.84.4. 5634

22. S. Straetemans, J. De Schepper, M. Thomas, S. Tenoutasse, V. Beauloye, R. Rooman, Criteria for first-year growth response to growth hormone treatment in prepubertal children with growth hormone deficiency: do they predict poor adult height outcome? Front Endocrinol. 10, 792 (2019). https://doi.org/10.3389/fendo. 2019.00792

23. P. Bang, R. Bjerknes, J. Dahlgren, L. Dunkel, J. Gustafsson, A. Juul, B. Kriström, P. Tapanainen, V. Aberg, A comparison of different definitions of growth response in short prepubertal children treated with growth hormone. Horm. Res. Paediatr. 75, 335-345 (2011). https://doi.org/10.1159/000322878

24. E. Koledova, G. Stoyanov, L. Ovbude, P.S.W. Davies, Adherence and long-term growth outcomes: results from the easypod() connect observational study (ECOS) in paediatric patients with growth disorders. Endocr. Connect 7, 914-923 (2018). https://doi. org/10.1530/ec-18-0172

25. M.C. Maggio, B. Vergara, P. Porcelli, G. Corsello, Improvement of treatment adherence with growth hormone by easypod device: experience of an Italian centre. Ital. J. Pediatr. 44, 113 (2018). https://doi.org/10.1186/s13052-018-0548-z

26. C. Centonze, C. Guzzetti, G. Orlando, S. Loche, E.I. Italian, Adherence to growth hormone $(\mathrm{GH})$ therapy in naive to treatment GH-deficient children: data of the Italian Cohort from the Easypod Connect Observational Study (ECOS). J. Endocrinol. Invest 42, 1241-1244 (2019). https://doi.org/10.1007/s40618-019-01046-1

27. C.L. Acerini, D. Segal, S. Criseno, K. Takasawa, N. Nedjatian, S. Rohrich, M. Maghnie, Shared decision-making in growth hormone therapy-implications for patient care. Front Endocrinol. 9, 688 (2018). https://doi.org/10.3389/fendo.2018.00688

28. G.A. Kamp, J.J. Waelkens, S.M. de Muinck Keizer-Schrama, H. A. Delemarre-Van de Waal, L. Verhoeven-Wind, A.H. Zwinderman, J.M. Wit, High dose growth hormone treatment induces acceleration of skeletal maturation and an earlier onset of puberty in children with idiopathic short stature. Arch. Dis. Child 87, 215-220 (2002). https://doi.org/10.1136/adc.87.3.215

29. M.J. Kang, E.Y. Kim, Y.S. Shim, H.R. Jeong, H.J. Lee, S. Yang, I.T. Hwang, Factors affecting bone age maturation during 3 years of growth hormone treatment in patients with idiopathic growth hormone deficiency and idiopathic short stature: Analysis of data from the LG growth study. Medicine 98(14), e14962 (2019). https://doi.org/10.1097/md.0000000000014962

30. G. Gacs, E. Hosszu, The effect of socio-economic conditions on the time of diagnosis and compliance during treatment in growth hormone deficiency. Acta Paediatr. Hung. 31, 215-221 (1991)

31. S. De Pedro, M. Murillo, I. Salinas, M.L. Granada, M. Martinez, M. Puig-Domingo, A. Andreu, J. Bel, Variability in adherence to rhGH treatment: socioeconomic causes and effect on children's growth. Growth Horm. IGF Res. 26, 32-35 (2016). https://doi.org/ 10.1016/j.ghir.2015.12.002 